\title{
Anti-nuclear antibody-negative immunoglobulin G4- associated autoimmune hepatitis mimicking lymphoproliferative disorders
}

\author{
Min Kyu Kang ${ }^{1}$, Jung Gil Park ${ }^{1}$, Joon Hyuk Choi ${ }^{2}$ \\ ${ }^{1}$ Department of Internal Medicine, Yeungnam University College of Medicine, Daegu, Korea \\ ${ }^{2}$ Department of Pathology, Yeungnam University College of Medicine, Daegu, Korea
}

Received: February 20, 2020

Revised: March 6, 2020

Accepted: March 9, 2020

Corresponding author:

Jung Gil Park

Department of Internal Medicine,

Yeungnam University College of

Medicine, 170 Hyeonchung-ro,

Nam-gu, Daegu 42415, Korea

Tel: +82-53-620-3316

Fax: +82-53-654-8386

E-mail:gsnrs@naver.com
Immunoglobulin G4 (IgG4)-associated autoimmune hepatitis (AlH) is a very rare subtype of autoimmune hepatitis and characterized by marked elevated serum IgG and hepatic infiltration of IgG4-expressing plasma cells. Pathologic confirmation of hepatic lgG4-expressing plasma cells is usually required for the final diagnosis of IgG4-associated AlH. Herein, we report the case of a 47-year-old female diagnosed with autoantibody-negative IgG4-associated AlH mimicking lymphoproliferative disorders.

Keywords: Autoimmune hepatitis; Immunoglobulin G; Immunoglobulin G4-related disease; Plasma cells; Prednisolone

\section{Introduction}

Autoimmune hepatitis (AIH) is an autoimmune liver disease characterized by hypergammaglobulinemia, the presence of serum autoimmune antibodies, and interface hepatitis. AIH is treated with immunosuppressants, including glucocorticoids, with or without azathioprine [1-3]. The diagnosis of AIH is usually made according to a scoring system, such as the Revised International Autoimmune Hepatitis Group (IAIHG) scoring system, due to heterogeneous clinical manifestations [4]. Recently, a new disease entity called Immunoglobulin G4 (IgG4)-associated AIH, which is different from classic AIH, has been described [5]. IgG4-associated $\mathrm{AIH}$, as a subtype of $\mathrm{AIH}$, is a rare disease characterized by the hepatic accumulation of IgG4-expressing plasma cells with markedly elevated serum IgG4 levels [6].

Differential diagnosis involves observation of markedly elevated serum IgG levels, presence of rouleaux formation in the peripheral smear, and low albumin/globulin ratios expressed in mono or polyclonal gammopathy in order to differentiate the condition from lymphoproliferative disorders such as multiple myeloma [7]. We report on a 47-year-old female with autoantibody-negative IgG4-related AIH that mimicked a lymphoproliferative disorder.

\section{Case}

All authors declare that written informed consent was obtained from the patient for publication of this case report and accompanying images. This study was approved by the Institutional Review Board of the Yeungnam University Hospital (IRB No: 202003-026).

A 47-year-old female visited our clinic for evaluation of abnormal liver function tests on a health-check examination. She had a previous history of a contrast allergy. She did not have any significant symptoms. There were no abnormal findings on physical ex- 

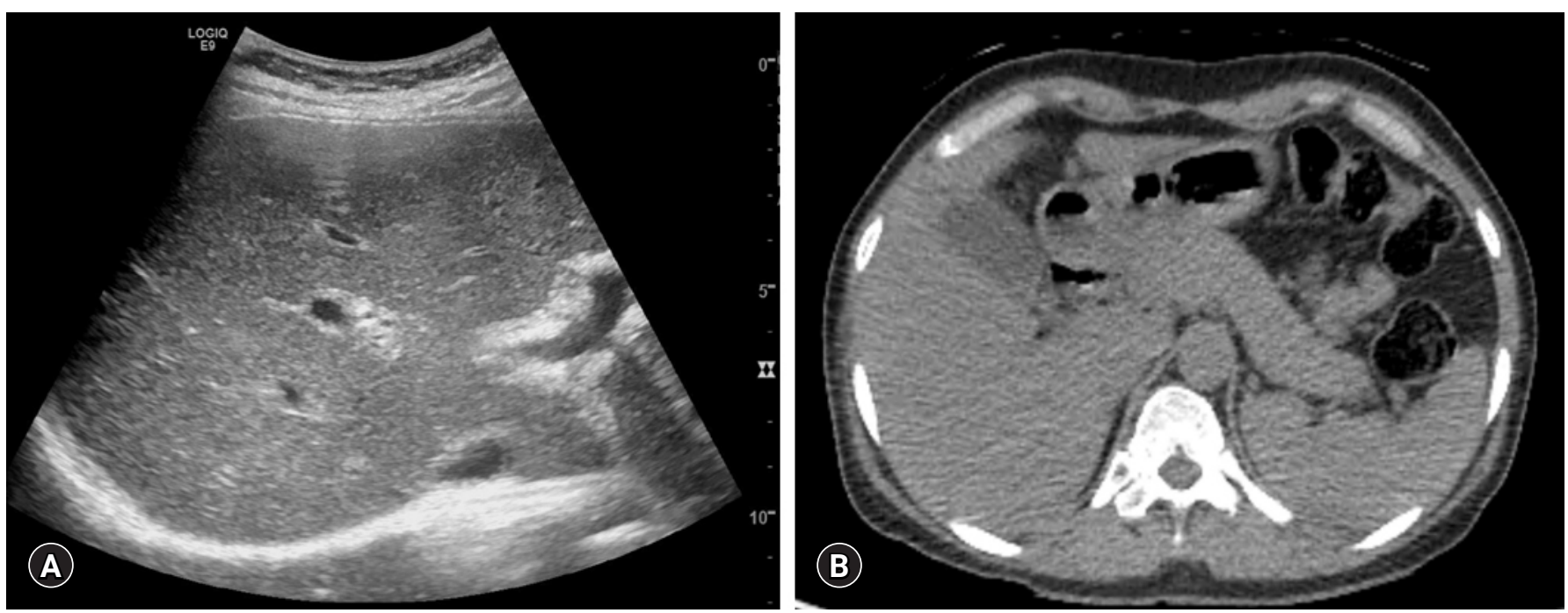

Fig. 1. Abdominal sonography and computed tomography showing $(A)$ increased echogenicity of the liver parenchyma with heterogeneous echotexture and (B) normal pancreas without significant evidence of autoimmune pancreatitis.

amination. Abdominal ultrasound and non-contrast computed tomography revealed coarsened hepatic echotexture, without any biliary duct abnormalities, and no evidence of pancreatitis such as peripancreatic swelling or a sausage-like lesion (Fig. 1). Blood chemistry revealed the following: white blood cells, 3,650/ $\mu \mathrm{L}$; hemoglobin, $12 \mathrm{~g} / \mathrm{dL}$; platelets, $294 \times 10^{3} / \mu \mathrm{L}$; serum total protein, $11.03 \mathrm{~g} / \mathrm{dL}$; serum albumin, $3.63 \mathrm{~g} / \mathrm{dL}$; total bilirubin, 1.02 $\mathrm{mg} / \mathrm{dL}$; serum aspartate aminotransferase (AST), $610 \mathrm{IU} / \mathrm{L}$; alanine aminotransferase (ALT), $221 \mathrm{IU} / \mathrm{L}$; alkaline phosphatase (ALP), $102 \mathrm{IU} / \mathrm{L}$; gamma-glutamyl transferase (GGT), $176 \mathrm{IU} /$ L; amylase, $65 \mathrm{IU} / \mathrm{L}$; lipase, $54 \mathrm{IU} / \mathrm{L}$; and prothrombin time-international normalized ratio, 1.12 .

Additional serologic tests, including serum hepatitis B surface antigen, hepatitis $\mathrm{C}$ antibody, anti-nuclear antibody (ANA), anti-smooth muscle antibody (SMA), anti-mitochondria antibody, anti-neutrophil cytoplasmic antibody, anti-liver kidney microsomal type 1 antibody, and other viral tests—including Epstein-Barr virus and cytomegalovirus-were all negative. However, she exhibited a markedly elevated serum IgG level at $6,614 \mathrm{mg} / \mathrm{dL}$ (range, 700-1,600 mg/dL). Peripheral blood smear revealed the rouleaux formation of the red blood cells (RBC).

The patient was referred to the Department of Hematology to evaluate the possibility of a lymphoproliferative disorder, such as multiple myeloma (MM). Serum and urine protein electrophoresis, free light chain ratio, skeletal survey, and bone marrow aspiration were performed. All were normal with the exception of an elevated serum IgG4 subclass level, which was $221.3 \mathrm{mg} / \mathrm{dL}$ (range, $6-120 \mathrm{mg} / \mathrm{dL}$ ).

A percutaneous ultrasound-guided liver biopsy was performed.
The pathologic results revealed moderate spotty necrosis and interface hepatitis with highly elevated IgG4-positive plasma cells (10-15/high power field [HPF]), consistent with AIH (Fig. 2). The pretreatment revised IAIHG scoring was 17, consistent with a definite diagnosis of AIH. Detailed IAIHG scoring was as follows: histological feature, 4; no drug and alcohol history, 3; negative findings of viral markers, 3 ; hypergammaglobulinemia, 3 ; ALP/AST ratio $<1.5$, 2; and female, 2.

Initially, she was treated with $60 \mathrm{mg}$ prednisolone daily, which was tapered by $10 \mathrm{mg}$ prednisolone weekly for 3 weeks. After 3 weeks, her laboratory test results were much improved as follows: AST, 25 IU/L; ALT, 23 IU/L; GGT, 67 IU/L; and IgG, 2,067 $\mathrm{mg} / \mathrm{dL}$. Subsequently, $50 \mathrm{mg}$ azathioprine was added for maintenance treatment, and $30 \mathrm{mg}$ prednisolone was tapered by $5 \mathrm{mg}$ weekly for 4 weeks. After 4 weeks, her laboratory test results were slightly worsened as follows: AST, 57 IU/L; ALT, 65 IU/L; GGT, $103 \mathrm{IU} / \mathrm{L}$; and IgG, $1,367 \mathrm{mg} / \mathrm{dL}$. Considering the risk of possible worsening after early prednisone withdrawal, we increased the dose of prednisolone up to $20 \mathrm{mg}$ and then slowly tapered every 2 weeks. After 1 month, all laboratory test results normalized (Fig. 3).

\section{Discussion}

In our case, the initial presumptive diagnosis was monoclonal or polyclonal gammopathy, such as MM or other lymphoproliferative diseases, based on the initial serological results including those for inverted albumin/globulin ratio $(\mathrm{A} / \mathrm{G})$ ratio (0.33), elevated serum $\mathrm{IgG}$, rouleaux formation of $\mathrm{RBC}$, and negative serologic autoimmune markers. However, based on the results of the 

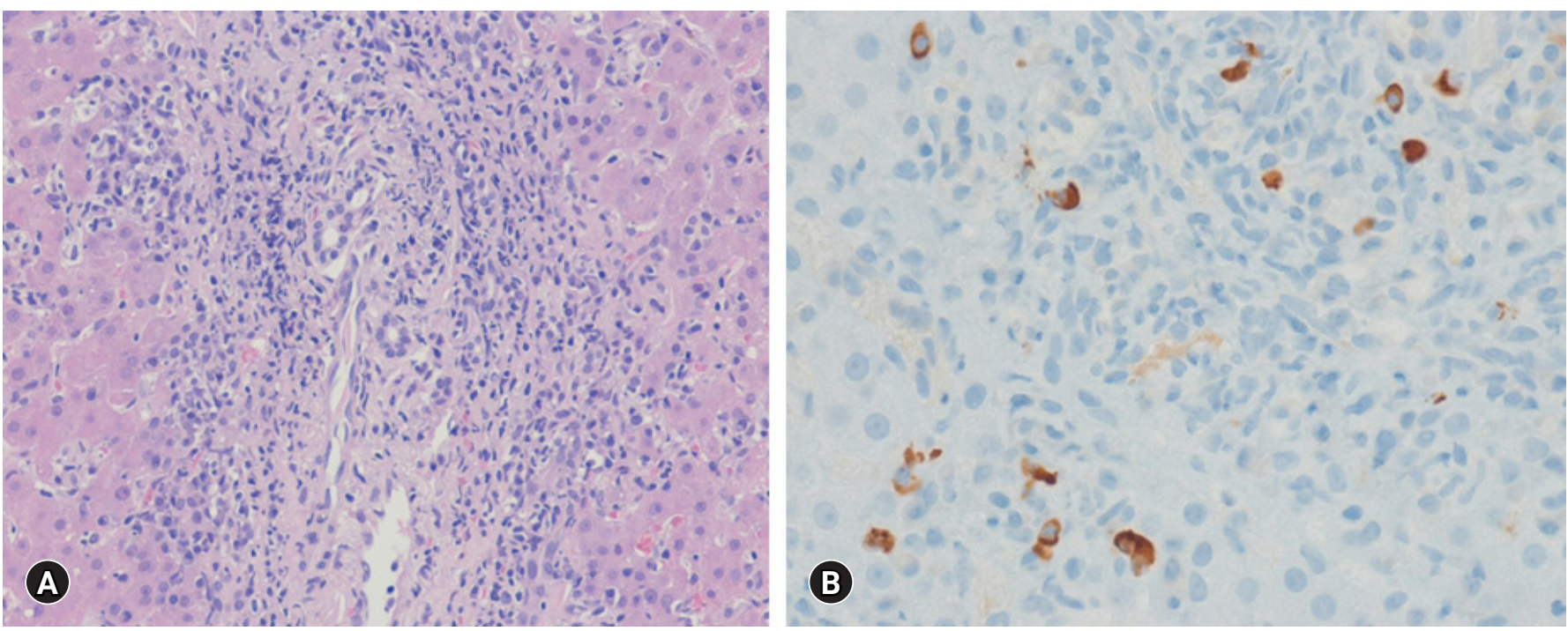

Fig. 2. Histologic findings of liver. (A) Moderate interface hepatitis with lymphocytes and plasma cells infiltration in the portal tract is present (hematoxylin-eosin stain, x200). (B) Immunoglobulin G4-positive plasma cells are seen (immunohistochemical stain, x400).

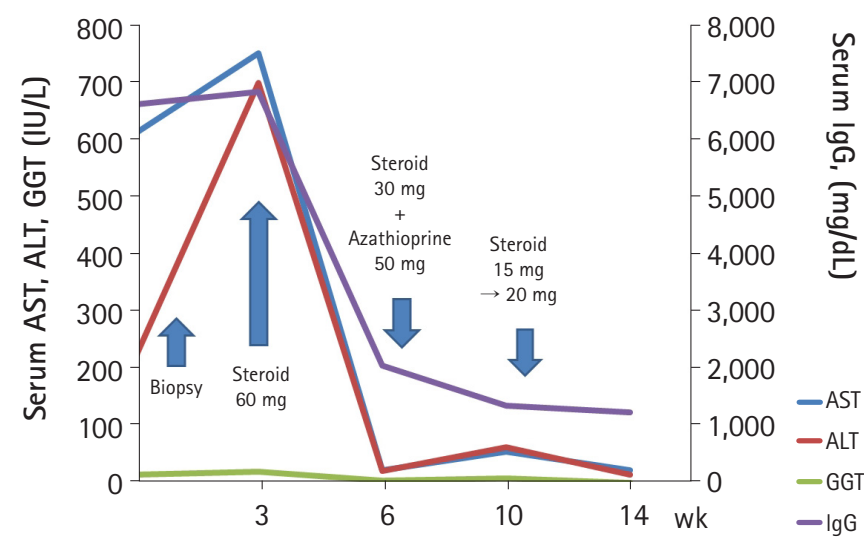

Fig. 3. The clinical course of the patient. AST, aspartate aminotransferase; ALT, alanine aminotransferase; GGT, gamma-glutamyl transferase; $\operatorname{lgG}$, immunoglobulin $\mathrm{G}$.

liver biopsy and elevated serum IgG4 levels, the final diagnosis was IgG4-associated AIH which was treated with prednisolone and azathioprine.

Previous studies of IgG4-associated AIH are summarized in Table 1 [6,8-11]. Recently, a new disease entity called IgG4-associated AIH, which is different from classic AIH, has emerged [5]. Umemura et al. $[5,6]$ had proposed that IgG4-AIH, as a subtype of $\mathrm{AIH}$, is a rare disease characterized by the hepatic accumulation of IgG4-expressing plasma cells ( $\geq 10$ IgG4 plasma cells per $\mathrm{HPF}$ ) with markedly elevated serum IgG levels ( $\geq 135 \mathrm{mg} / \mathrm{dL}$ ). Of the 60 patients with AIH in Japan, only two (3\%) were diag- nosed with IgG4-associated AIH [6]. The median values of IgG and IgG4 levels were 4,015 mg/dL and $560 \mathrm{mg} / \mathrm{dL}$, respectively. These levels were higher than those of classic AIH (IgG, 2,940 $\mathrm{mg} / \mathrm{dL}$ and IgG4, $22 \mathrm{mg} / \mathrm{dL}$, respectively) [6]. Also, two patients were diagnosed with IgG4-associated AIH, with positive ANA and SMA ( 1 of 2 patients), which was defined as a subtype of AIH [6]. In a Western study, based on Umemura's histologic criterion, the prevalence of IgG4-associated AIH was $25 \%$ (7 patients). The presence of the autoimmune antibodies was not significantly different from IgG4-associated AIH and classic AIH [8].

In our case, serum IgG and IgG4 levels were $6,614 \mathrm{mg} / \mathrm{dL}$ and $221.3 \mathrm{mg} / \mathrm{dL}$, respectively. These markedly elevated IgG levels were four times greater than the normal upper level, which satisfied Umemura's serologic criterion. In the liver, IgG4-bearing plasma cells of 10-15 HPF also met Umemura's histologic criterion for diagnosis of IgG4-associated AIH. Owing to the initially all-negative autoimmune antibody serology, marked elevated hypergammaglobulinemia, and inverted $\mathrm{A} / \mathrm{G}$ ratio in our case, we preferentially considered a lymphoproliferative disorder such as MM. Though most IgG4-associated AIH had positive ANA or SMA $[6,8]$, the frequency of autoantibody-negative AIH in patients with acute and acute-severe clinical features reached $7 \%$ in one study [12]. Therefore, though patients show negative ANA, hypergammaglobulinemia, and elevated liver enzymes, additional serum IgG4 tests would be needed for differential diagnosis of IgG4-associated AIH. Then, when IgG4 is elevated, a subsequent liver biopsy is required for the definite diagnosis of IgG4-associated AIH, as with our case. 
Table 1. Autoantibody-negative immunoglobulin G4-associated autoimmune hepatitis

\begin{tabular}{llccccc}
\hline Study & Country & $\begin{array}{c}\text { IgG4-AlH/autoanti- } \\
\text { body negative lgG4- } \\
\text { AlH (no.) }\end{array}$ & $\begin{array}{c}\text { Diagnostic criteria for lgG4- } \\
\text { AlH (IgG4-positive plasma } \\
\text { cells/HPF) }\end{array}$ & $\begin{array}{c}\text { IgG/lgG4 levels } \\
\text { (median, mg/dL) }\end{array}$ & $\begin{array}{c}\text { IAlHG score } \\
\text { (median) }\end{array}$ & $\begin{array}{c}\text { Combination therapy } \\
\text { (PD+azathioprine) }\end{array}$ \\
\hline Uemmura et al. [6] & Japan & $2 / 0$ & $>10$ & $4,015 / 560$ & 17 & Yes \\
Chung et al. [10] & Japan & $9 / 0$ & $>5$ & NA & NA & Only PD \\
Amarapurkar et al. [9] & India & $10 / \mathrm{NA}$ & $>5$ & $1,600 / 300$ (3 patients) & NA & Yes \\
Canivet et al. [8] & France & $7 / \mathrm{NA}$ & $>10$ & $2,500 / \mathrm{NA}$ & NA & Yes \\
Aydemir et al. [11] & Turkey & $6 / \mathrm{NA}$ & $>10$ & $2,636 / \mathrm{NA}$ & 17.8 & Yes \\
This case & Korea & $1 / 1$ & $>10$ & $6,614 / 560$ & 17 & Yes \\
\hline
\end{tabular}

IgG4-AlH, immunoglobulin G4-associated autoimmune hepatitis; HPF, high power field (x400); IAIHG, International Autoimmune Hepatitis Group; PD, prednisolone; NA, not applicable.

There can be some conflicts regarding IgG4-related disease (IgG4-RD) and IgG4-associated AIH, as noted by several studies [6,8-10]. The clinical features of IgG4-RD, which are similar to elevated IgG and IgG4 levels, include multiple organ involvement with storiform fibrosis. IgG4-RD preferentially affects the pancreas, bile duct, kidneys, and salivary glands, but rarely involves the liver $[13,14]$. However, it is still uncertain whether IgG4-associated AIH is a subtype of AIH or hepatic involvement of IgG4-RD. In our opinion, when evidence of multiple organ involvement and pathologic storiform fibrosis are not seen, the possibility of IgG4-associated AIH is higher than IgG4-RD.

Complete normalization of ALT and IgG levels is the clinical target for the treatment of AIH [15]. The treatment of IgG4-AIH is not much different from that of $\mathrm{AIH}$, and involves glucocorticoids with or without azathioprine [16]. The efficacy of these treatments could be predicted by the accumulation of plasma cells in the liver [16]. However, some studies reported that the time to return to ALT normalization after administration of glucocorticoids is shorter in patients with IgG4-associated AIH than in those with classic AIH (3.7 months vs. 6.7 months, respectively) $[10,11]$. In our study, mild flare-up while switching from a glucocorticoid to combination therapy was observed, which may have resulted from rapid tapering of the glucocorticoid dose by $5 \mathrm{mg}$ weekly. The early withdrawal of immunosuppressants could be a risk factor for flares of AIH, which require increased doses of glucocorticoids [15]. Therefore, monitoring intervals should be adjusted according to the individual clinical response, which could be extended to 1-3 months with combination treatment [15].

In conclusion, IgG4-associated AIH should be contemplated in patients with marked hypergammaglobulinemia and abnormal liver function test results, even when the autoimmune test is negative. Liver biopsy should be required for the diagnosis of IgG4-associated AIH in these patients with elevated serum IgG4.

\section{Acknowledgements}

\section{Conflicts of interest}

Joon Hyuk Choi serves as an editor-in-chief of the Yeungnam University Journal of Medicine, but has no role in the decision to publish this article. Except for that, no potential conflict of interest relevant to this article was reported.

\section{Author contributions}

Conceptualization: MKK, JGP, JHC; Data curation: MKK; Methodology: MKK, JGP; Investigation: MKK, JHC; Resources: JHC; Project administration: JHC; Visualization: JHC; Writing-original draft: MKK; Writing-review \& editing: JGP.

\section{ORCID}

Min Kyu Kang, https://orcid.org/0000-0002-1435-3312

Jung Gil Park, https://orcid.org/0000-0001-5472-4731

Joon Hyuk Choi, https://orcid.org/0000-0002-8638-0360

\section{References}

1. Krawitt EL. Autoimmune hepatitis. N Engl J Med 2006; 354:54-66.

2. Manns MP, Vogel A. Autoimmune hepatitis, from mechanisms to therapy. Hepatology 2006;43(2 Suppl 1):S132-44.

3. Vergani D, Longhi MS, Bogdanos DP, Ma Y, Mieli-Vergani G. Autoimmune hepatitis. Semin Immunopathol 2009;31:42135.

4. Alvarez F, Berg PA, Bianchi FB, Bianchi L, Burroughs AK, Cancado EL, et al. International Autoimmune Hepatitis Group Report: review of criteria for diagnosis of autoimmune hepatitis. J Hepatol 1999;31:929-38.

5. Umemura T, Zen Y, Hamano H, Ichijo T, Kawa S, Nakanuma Y, et al. IgG4 associated autoimmune hepatitis: a differential diag- 
nosis for classical autoimmune hepatitis. Gut 2007;56:1471-2.

6. Umemura T, Zen Y, Hamano H, Joshita S, Ichijo T, Yoshizawa $\mathrm{K}$, et al. Clinical significance of immunoglobulin G4-associated autoimmune hepatitis. J Gastroenterol 2011;46(Suppl 1):4855.

7. Rajkumar SV. Multiple myeloma: 2018 update on diagnosis, risk-stratification, and management. Am J Hematol 2018; 93:981-1114.

8. Canivet CM, Anty R, Patouraux S, Saint-Paul MC, Lebeaupin C, Gual P, et al. Immunoglobulin G4-associated autoimmune hepatitis may be found in Western countries. Dig Liver Dis 2016;48:302-8.

9. Amarapurkar AD, Amarapurkar DN. Immunoglobulin IgG4 and autoimmune hepatitis. Trop Gastroenterol 2015;36:112-7.

10. Chung H, Watanabe T, Kudo M, Maenishi O, Wakatsuki Y, Chiba T. Identification and characterization of IgG4-associated autoimmune hepatitis. Liver Int 2010;30:222-31.
11. Aydemir Y, Akcoren Z, Demir H, Saltik Temizel IN, Ozen H, Yuce A. Clinical and histopathological features of immunoglobulin G4-associated autoimmune hepatitis in children. J Gastroenterol Hepatol 2019;34:742-6.

12. Czaja AJ. Autoantibody-negative autoimmune hepatitis. Dig Dis Sci 2012;57:610-24.

13. Stone JH, Zen Y, Deshpande V. IgG4-related disease. N Engl J Med 2012;366:539-51.

14. Watanabe T, Minaga K, Kamata K, Kudo M, Strober W. Mechanistic insights into autoimmune pancreatitis and IgG4-related disease. Trends Immunol 2018;39:874-89.

15. European Association for the Study of the Liver. EASL Clinical Practice Guidelines: autoimmune hepatitis. J Hepatol 2015; 63:971-1004.

16. Minaga K, Watanabe T, Chung H, Kudo M. Autoimmune hepatitis and IgG4-related disease. World J Gastroenterol 2019; 25:2308-14. 